\title{
Efficiency of dung application on rice agro- ecosystems in Kuban
}

\author{
Ashad Sheudzhen ${ }^{1,2^{*}}$, Oksana Gutorova ${ }^{1}$, and Hazret Hurum ${ }^{1}$ \\ ${ }^{1}$ Kuban State Agrarian University named after I.T. Trubilin, 350044, Kalinina, 13, Krasnodar, \\ Russian Federation \\ ${ }^{2}$ Federal scientific rice centre, 350921, Belozerny, 3, Krasnodar, Russian Federation
}

\begin{abstract}
The effect of the combined application of dung and nitrification inhibitor Entec FL DMPP on the loss of ammonium nitrogen from meadow chernozem soil (corresponding to Gleyic Chernozem in WRB) under the conditions of rice cultivation in the Kuban was studied. On the rice irrigation system, a field experiment was performed with autumn and spring incorporation of dung at a rate of $30 \mathrm{t} / \mathrm{ha}$, both separately and with the addition of a nitrification inhibitor against the background of mineral fertilizers. It was found that the inclusion of a nitrification inhibitor in the dung contributed to a decrease in nitrogen losses by $6.7-15.0 \%$ during their incorporation in autumn and by $10.8-18.1 \%$ in spring, occurring as a result of denitrification and leaching of nitrates, and optimum conditions of nitrogen nutrition for rice plants. A less pronounced effect of the nitrification inhibitor was noted during its autumn incorporation with dung, which is associated with a lower air temperature in autumn and a longer period from fertilization to rice sowing.
\end{abstract}

\section{Introduction}

The Krasnodar Territory is the main rice-growing region in the Russian Federation, where the annual area under this crop reaches 120-130 th ha. The growth in productivity that has been outlined in recent years is caused by the development and deployment of energy and soil saving technologies and the creation of new adaptive rice cultivars. However, there is the decrease in soil fertility against the background of an increase in rice productivity. One of the ways of its preservation and reproduction, optimization of the regimes of organic matter and the conditions of mineral nutrition of rice plants is the inclusion of liquid manure in the fertilization system, which will also allow the most complete use of animal excrement and create conditions for their utilization.

Dung improves the agrophysical, physicochemical properties of rice field soils, increases their buffering capacity, the amount of absorbed bases in the soil-absorbing complex, the content of organic matter, provides a deficit-free humus balance, enhances microbiological processes, enriches them with elements of ash nutrition [1-3]. However, the nitrogen introduced with dung can be lost in the form of ammonia and nitrous oxide due to various biochemical reactions. One of the ways to reduce nitrogen losses from the root

* Corresponding author: ashad.sheudzhen@mail.ru 
layer of soils in rice fields, pollution of environmental objects and increase the efficiency of applied liquid manure is the use of various nitrification inhibitors (nitropyrene, terrazol, 1carbamoyl-3 (5) -methylpyrazole - KMP, dicyandiamide, etc.). [4-6].

In connection with the above, the research was aimed to study the effect of the combined application of dung and nitrification inhibitor Entec FL DMPP on nitrogen losses from meadow chernozem soil in the conditions of rice cultivation in the Kuban.

\section{Materials and Methods}

The research was performed on a rice irrigation system in the Krasnoarmeisky district of the Krasnodar Territory. The climate of the region is characterized by moderate continental, mild winters, an insignificant amount of positive temperatures above $10{ }^{\circ} \mathrm{C}-3600{ }^{\circ} \mathrm{C}$ and a small average annual rainfall of $589 \mathrm{~mm}$. Pursuant to the geomorphological map of the Krasnodar Territory, the territory of the region belongs to the ancient deltaic accumulativealluvial plain of the Kuban River; in terms of the soil-geographical zoning - to the AzovCiscaucasian soil province of the steppe zone of ordinary and southern chernozems, the soil district of the lower reaches of the Kuban River with the distribution of soils of meadowsteppe and meadow types. The soil cover of the area under consideration is mainly represented by the meadow chernozem soil [7] (corresponding to Gleyic Chernozem in WRB [8]), located on ridges and ridge-like near-rises of the flooded plain.

Agrochemical characteristics of meadow chernozem soil: $\mathrm{pH}_{\mathrm{H} 2 \mathrm{O}}-6.6$ units; humus $3.3 \% ; \mathrm{N}_{\text {tot. }}-0.220 \% ; \mathrm{C}_{\mathrm{gk}}: \mathrm{C}_{\mathrm{fk}}=1.86 ; \mathrm{P}_{2} \mathrm{O}_{5}-39.5 \mathrm{mg} / \mathrm{kg} ; \mathrm{K}_{2} \mathrm{O}-240 \mathrm{mg} / \mathrm{kg}$ [9].

The research objects are liquid manure and nitrification inhibitor Entec FL DMPP (DMPP - 3,4 dimethylpyrazole phosphate) [10].

A field experiment was performed on the rice irrigation system. The dung was embedded in the soil in autumn and spring at a rate of $30 \mathrm{t} /$ ha with heavy discs to a depth of $8-10 \mathrm{~cm}$. The nitrification inhibitor Entec FL was added to the dung tank and mixed thoroughly. In all variants of the experiment, ammophos was introduced before rice sowing. In the variant with the technology of rice cultivation adopted on the farm, in addition to ammophos, carbamide and potassium chloride were additionally introduced [11]. The experiment scheme is as follows:

1. Control (no fertilizers).

2. Rice cultivation technology on the farm.

3. Dung, $30 \mathrm{t} / \mathrm{ha}$ (autumn).

4. Dung, $30 \mathrm{t} / \mathrm{ha}+$ nitrification inhibitor EntecFL (autumn).

5. Dung, $30 \mathrm{t} / \mathrm{ha}$ (spring).

6. Dung, $30 \mathrm{t} / \mathrm{ha}+$ nitrification inhibitor EntecFL (spring).

All variants of the experiment provided for the simultaneous sampling of the soil from the arable layer of $0 \ldots .20 \mathrm{~cm}$ : before sowing, during the growing season (seedlings, tillering, sweeping) and after harvesting rice.

The redox potential $(\mathrm{Eh}, \mathrm{mV})$ and the activity of hydrogen ions $(\mathrm{pH})$ were measured in the selected soil samples with undisturbed composition by the potentiometric method using a Mettler Toledo $\mathrm{pH}$ meter [12]. Nitrate nitrogen was extracted from the soil with $0.05 \%$ $\mathrm{K}_{2} \mathrm{SO}_{4}$ at a soil to solution ratio of 1: 5 and was determined by the colorimetric method pursuant to Grandval-Lyazh technique. When nitrates interact with disulfophenolic acid in an alkaline medium, yellow nitro derivatives are formed. The method allows to determine not less than $0.02 \mathrm{mg}$ of $\mathrm{N}^{-\mathrm{NO}_{3}}$ in $100 \mathrm{ml}$ of solution [12]. The content of exchangeabsorbed ammonium in the soil was determined in a $2 \% \mathrm{KCl}$ solution applying the phenol method. The method is based on Berthelot's reaction, as a result of which, when ammonia interacts with phenol in the presence of the oxidizing agent sodium hypochlorite, 
indophenol is formed, which turns the solution blue. The reaction takes place in an alkaline medium [12].

The research results were statistically evaluated. The arithmetic mean and standard deviation $(\sigma)$ was calculated [13].

\section{Results and Discussion}

Rice agrocenosis is a complex agroecological multicomponent system. The most important factor determining the changes and direction of soil processes in it is the redox state [1415]. The flooding of the rice field caused the replacement of the oxidative processes with the reduction ones. Before rice sowing, the redox potential was $480 \mathrm{mV}(\sigma= \pm 14 \mathrm{mV})$. A month after the creation of the water layer, in the germination phase, the Eh values decreased by $59 \mathrm{mV}$ in the control and by $68-164 \mathrm{mV}$ in the variants with fertilizers. With an increase in the duration of the time spent by the soil in the submerged state, the redox potential sharply decreased. Its negative values are recorded in the rice flowering phase: $100 \ldots-187 \mathrm{mV}$. The difference in the interval between the Eh values before the creation of a water layer on the paddy field and the period of intensive development of anaerobic conditions in the soil (flowering phase) was $580 \ldots 667 \mathrm{mV}$. After collecting irrigation water from the check and creating aerobic conditions in the soil, the redox potential increased again (Figure 1).

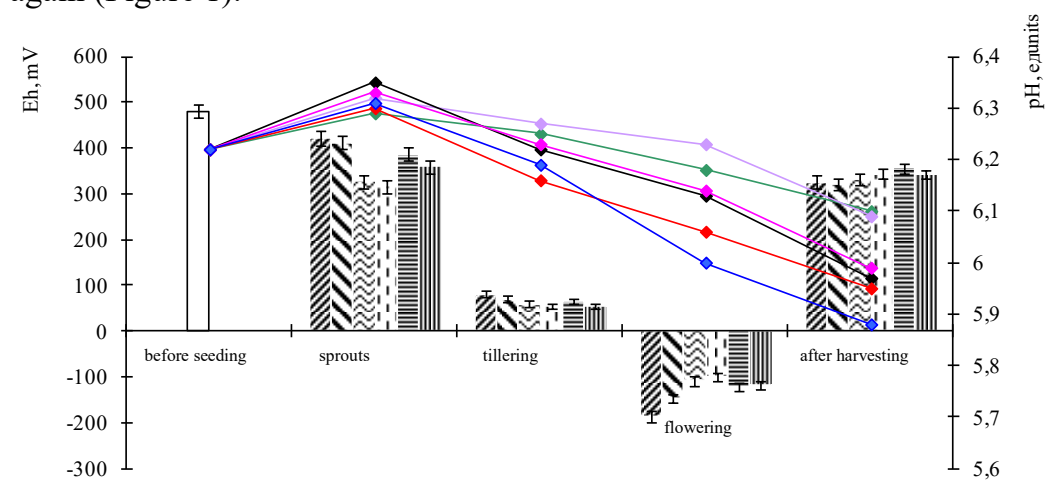

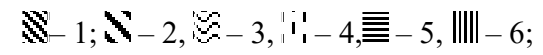

$$
\begin{aligned}
& \multimap 1 \multimap 2 \multimap 3 \multimap 4 \multimap 5 \multimap 6
\end{aligned}
$$

Fig. 1. Dynamics of redox potential and $\mathrm{pH}$ value in soil under rice: 1-6 - the options for the experiment are indicated in the materials and methods section.

The greatest decrease in Eh values was observed with the autumn application of dung, both separately and together with a nitrification inhibitor. In the rice germination phase, the Eh values decreased by 153 and $164 \mathrm{mV}$; in the flowering of plants, minus values of - $109 \ldots$ $-100 \mathrm{mV}$, which is 12 and $18 \mathrm{mV}$ lower in comparison with the spring planting, respectively.

Before the flooding of the rice field, the meadow chernozem soil was characterized by rather close values of the content of nitrate $\left(\mathrm{NO}_{3}{ }^{-}\right)$and ammonium nitrogen $\left(\mathrm{NH}_{4}^{+}\right)$. With the creation of a reduced environment in it, the amount of nitrates decreased by 2-4 times. At the same time, in the seedling phase, their maximum content was observed when using some mineral fertilizers. The autumn and spring incorporation of dung into the soil contributed to a more intensive recovery of nitrates. In the tillering phase of rice, their presence did not exceed $0.1 \mathrm{mg} / \mathrm{kg}$ and $0.2-0.7 \mathrm{mg} / \mathrm{kg}$ in fertilized soil in the soil of the control variant, and nitrates were not detected during the ear formation of plants due to their 
reduction. A significant decrease in the content of $\mathrm{NO}_{3}{ }^{-}$was noted with the inclusion of a nitrification inhibitor in the dung. After the water was discharged from the rice paddies, the processes of nitrification in the soil were resumed and the content of nitrates increased (Table 1). Consequently, with the introduction of dung and a nitrification inhibitor, denitrification processes in the soil intensify, and the role of nitrates in nitrogen nutrition of plants during the growing season of rice becomes insignificant.

Table 1. Dynamics of the content of nitrate nitrogen in the soil under rice, $\mathrm{mg} / \mathrm{kg}$

\begin{tabular}{|c|c|c|c|c|c|}
\hline \multirow{2}{*}{ Option $^{\mathrm{a}}$} & \multirow{2}{*}{$\begin{array}{c}\text { Before } \\
\text { seeding }\end{array}$} & \multicolumn{3}{|c|}{ Vegetation phases } & \multirow{2}{*}{ After harvesting } \\
\cline { 3 - 5 } & & sprouts & tillering & ear formation & \\
\hline 1 & $14.3 \pm 1.1$ & $3.2 \pm 0.8$ & $0.1 \pm 0.01$ & none & $5.8 \pm 0.06$ \\
\hline 2 & $14.3 \pm 1.1$ & $7.3 \pm 0.6$ & $0.7 \pm 0.02$ & none & $7.1 \pm 0.09$ \\
\hline 3 & $14.3 \pm 1.1$ & $6.4 \pm 0.5$ & $0.7 \pm 0.04$ & traces & $6.6 \pm 0.07$ \\
\hline 4 & $14.3 \pm 1.1$ & $4.8 \pm 0.7$ & $0.3 \pm 0.02$ & none & $7.6 \pm 0.08$ \\
\hline 5 & $14.3 \pm 1.1$ & $6.0 \pm 0.6$ & $0.6 \pm 0.03$ & traces & $6.9 \pm 0.06$ \\
\hline 6 & $14.3 \pm 1.1$ & $5.1 \pm 0.5$ & $0.2 \pm 0.03$ & none & $7.9 \pm 0.08$ \\
\hline
\end{tabular}

a 1-6 - the options for the experiment are indicated in the materials and methods section.

Nitrogen, as a limiting nutrient, is available for rice mostly in ammonium form. Due to the flooding of soils and the creation of recovery processes in them during the growing season of rice, the transformation of nitrogen compounds occurs. During this period, its dominant form is exchange-absorbed ammonium.

After the flooding of the rice field, the content of ammonium nitrogen increased by 5.5 $15.4 \mathrm{mg} / \mathrm{kg}$, or 1.5-2.0 times compared with the pre-sowing period. This is associated with a decrease in the rate of immobilization of inorganic nitrogen by microorganisms due to a decrease in their number in the flooded soil and with the mineralization of organic nitrogencontaining compounds. In subsequent phases of plant development, the amount of exchange-absorbed ammonium in the soil gradually decreased due to its increased consumption by rice. And already by the tillering phase, the $\mathrm{NH}_{4}^{+}$content was $1.9-4.1$ $\mathrm{mg} / \mathrm{kg}$ less than in the germination phase. The discharge of water from the rice field in the phase of full ripeness of the grain affected the ammonification process and, as a result, the content of ammonium nitrogen in the soil decreased (Figure 2).

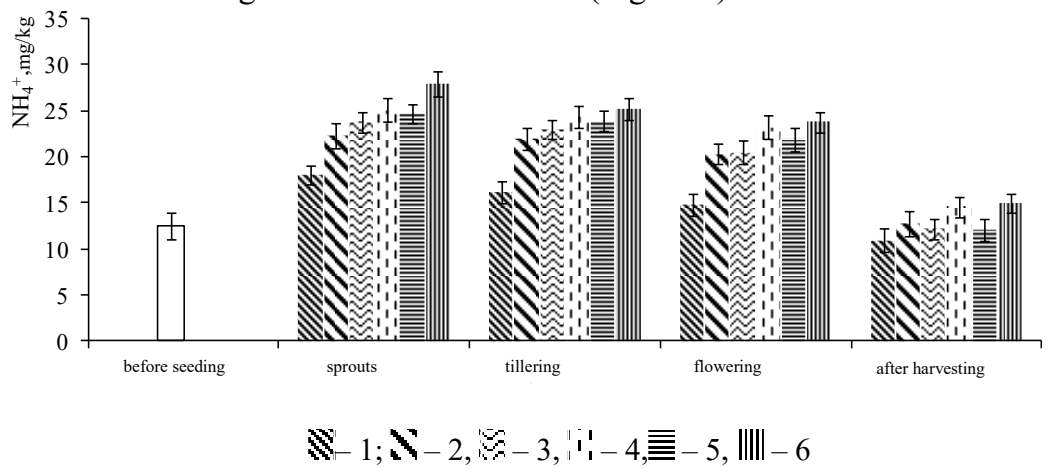

Fig. 2. Dynamics of the content of exchange-absorbed ammonium in the soil under rice: 1-6 - the options for the experiment are indicated in the materials and methods section.

The mineral fertilizers applied pursuant to the farm technology and dung both separately and together with a nitrification inhibitor did not change the nature of the dynamics of ammonium nitrogen, but influenced its content in the soil. In the rice germination phase, the 
amount of $\mathrm{NH}_{4}{ }^{+}$increased by $4.3-9.9 \mathrm{mg} / \mathrm{kg}$ relative to the control without fertilization, or by $23.9-55.0 \%$. A noticeable effect on the content of exchange-absorbed ammonium nitrogen was exerted by the introduction of dung into the soil. If, when applying some mineral fertilizers, its amount in the germination phase exceeded the control by $4.3 \mathrm{mg} / \mathrm{kg}$ $(23.9 \%)$, then when using dung in autumn and spring - $5.8 \mathrm{mg} / \mathrm{kg}(32.2 \%)$ and $6,7 \mathrm{mg} / \mathrm{kg}$ (37.2\%), and with joint autumn and spring embedding in soil with a nitrification inhibitor $7.1 \mathrm{mg} / \mathrm{kg}(39.4 \%)$ and $9.9 \mathrm{mg} / \mathrm{kg}(55.0 \%)$ respectively. The same excess of control was observed in the subsequent phases of rice vegetation - tillering, ear formation and full ripeness: $5.5-5.9 \mathrm{mg} / \mathrm{kg}(36.6-37.2 \%) ; 5.7-6.9 \mathrm{mg} / \mathrm{kg}(38.5-42.9 \%)$ and $7.1-7.8 \mathrm{mg} / \mathrm{kg}$ (48.0-48.4\%); 8.3-8.4 mg/kg (51.6-56.8\%) and 9.0-9.1 mg/kg (56.5-60.8\%), respectively.

In the variant with the introduction of mineral fertilizers, ammonium nitrogen in the soil, during the entry phase, contained $1.5 \mathrm{mg} / \mathrm{kg}(6.7 \%)$ less than when applying liquid manure from the fall and $2.4 \mathrm{mg} / \mathrm{kg}(10,8 \%)$ - from spring. In the tillering phase, the differences between the variants in the $\mathrm{NH}_{4}{ }^{+}$content decreased to 4.5 and $8.6 \%$, and in the sweeping phase - to 0.98 and $7.9 \%$, respectively. The combined use of dung and a nitrification inhibitor contributed to a greater accumulation of nitrogen in the soil. Its content exceeded the variant with only mineral fertilizers in the germination phase by $12.6 \%$ when incorporating manure in autumn and by $25.1 \%$ in spring; in tillering - by 10.9 and $14.5 \%$; in sweeping -14.3 and $17.2 \%$, respectively.

Before the rice harvest, when aerobic conditions prevailed in the fertilized soil with mineral fertilizers alone, the ammonium nitrogen content was $1.8 \mathrm{mg} / \mathrm{kg}(16.5 \%)$ more than in the control, and dung from autumn and spring - by $1.3 \mathrm{mg} / \mathrm{kg}(12.0 \%)$ and $1.2 \mathrm{mg} / \mathrm{kg}$ $(11.0 \%)$, respectively. During the autumn and spring incorporation of liquid manure with a nitrification inhibitor, the $\mathrm{NH}_{4}{ }^{+}$content exceeded the pre-sowing period by $2.1 \mathrm{mg} / \mathrm{kg}$ $(16.8 \%)$ and $2.5 \mathrm{mg} / \mathrm{kg}(20.0 \%)$, as well as control in the phase of full grain ripeness -3.7 $\mathrm{mg} / \mathrm{kg}(33.9)$ and $4.1 \mathrm{mg} / \mathrm{kg}(37.6 \%)$, option with mineral fertilizers - $1.9 \mathrm{mg} / \mathrm{kg}(15.0 \%)$ and $2.3 \mathrm{mg} / \mathrm{kg}(18.1 \%)$ and fertilized options only with liquid manure $-2.4 \mathrm{mg} / \mathrm{kg}(19.7 \%)$ and $2.9 \mathrm{mg} / \mathrm{kg}(24.0 \%)$, respectively.

Thus, the introduction of a nitrification inhibitor into the dung reduces the loss of ammonium nitrogen from the soil and increases the supply of plants with this nutrient during the entire growing season of rice. On average, nitrogen losses during the growing season decreased in comparison with the mineral background by $6.7-15.0 \%$ when applied in autumn and by $10.8-18.1 \%$ in spring. The less pronounced effect of the nitrification inhibitor during the autumn incorporation from dung is due to weather conditions. A lower air temperature in autumn and a longer time interval from fertilization to rice sowing could contribute to the leaching of nitrogen from the topsoil [16-17].

\section{Conclusion}

It is advisable to add the nitrification inhibitor Entec FL DMPP to regulate the nitrogen regime of meadow-chernozemic soil and ensure the effectiveness of dung on crops of rice agrocenoses. Their combined use reduces the loss of nitrogen in the ammonium form by $6.7-15.0 \%$ during embedding in autumn and by $10.8-18.1 \%$ in spring occurring as a result of denitrification and leaching of nitrates, as well as creates the optimum conditions for nitrogen nutrition for rice plants.

\section{Acknowledgements}

The research was performed with the financial support of the Kuban science Foundation in the framework of the scientific project № 20.1/48. 


\section{References}

1. Rice-growing system of the Krasnodar Territory (2005)

2. M. Siavoshi, A. Nasiri, S. Laware, Journal of Agricultural Science, 3 (2011)

3. K. Moe, A.Z. Htwe, T.T.P. Thu, Y. Kajihara, T. Yamakawa, Agriculture, 9 (2019)

4. K. Moe, S.M. Moh, A.Z. Htwea, Y. Kajihara, T. Yamakawa, Rice Science, 26 (2019)

5. Q. Yu, J. Ma, P. Zou et al., Environ Sci Pollut Res., 22 (2015)

6. K.A. Marsden, A.J. Marín-Martínez, A. Vallejo, P.W. Hill, D.L. Jones, D.R. Chadwick, Biology and Fertility of Soils, 52 (2016)

7. D. Fangueiro, A. Fernandes, J. Coutinho, H.N. Moreira, Communications in Soil Science and Plant Analysis, 40 (2009)

8. V.V. Egorov, V.M. Fridland, E.N. Ivanova, N.N. Rozov, V.A. Nosin, T.A. Friev, Classification and soil diagnostics of the USSR (1977)

9. World Reference Base for Soil Resources 2014. Update 2015. International soil classification system for naming soils and creating legends for soil maps (World Soil Resources Reports No. 106 FAO, Rome, 2015)

10. A. Kh. Sheudzhen, O.A. Gutorova, E.V. Shein, V.A. Romanenkov, IOP Conf. Ser.: Earth Environ. Sci., 368 (2019)

11. A.K. Sheudzhen, O.A. Gutorova, IOP Conf. Ser.: Earth Environ. Sci., 659 (2021)

12. A.V. Sokolov, Agrochemical Methods of Soil Examination (1975)

13. A.Kh. Sheudzhen, T.N. Bondareva, Agrochemical research methodology and statistical evaluation of their results (2015)

14. A. Kh. Sheudzhen, O.A. Gutorova ${ }_{2}$ IOP Conf. Ser.: Earth Environ. Sci., 941 (2020)

15. S.A. Nikolayeva, Eurasian Soil Science, 28 (1996)

16. C.S.Khind, F.N. Ponnamperuma, Plant and Soil, 59 (1981)

17. R.J. Buresh, S.K. De Datta, Biol Fertil Soils, 9 (1990) 